\title{
Casuística de leishmaniosis visceral canina registrada en Corrientes (Argentina) durante el período 2014-2016
}

\author{
Maidana, H.R. '; P.Gianeselli, M.2; Báez, A.D..; Cabrera, W.R. '; Llano, E.G. ${ }^{1}$ \\ ${ }^{1}$ Servicio Diagnóstico de Leishmaniosis Visceral Canina; ${ }^{2}$ Cátedra de Farmacología y Toxicología, \\ Fac.Cs.Veterinarias, Univ.Nac.Nordeste (UNNE), Corrientes, Argentina. \\ E-mail: hrm@vet.unne.edu.ar
}

\begin{abstract}
Resumen
Maidana, H.R.; P.Gianeselli, M.; Báez, A.D.; Cabrera, W.R.; Llano, E.G.: Casuística de leishmaniosis visceral canina registrada en Corrientes (Argentina) durante el período 2014-2016. Rev. Vet. 30: 1, 68-69, 2019. Durante los meses de febrero a octubre de los años 2014 a 2016 se investigó el padecimiento de leishmaniosis visceral en caninos atendidos en la Facultad de Ciencias Veterinarias de Corrientes, Argentina. El estudio se efectuó a través del método indirecto (detección de anticuerpos contra el antígeno rK39 en suero de sangre venosa) y la prueba directa (extracción de medula ósea por punción en distal de costillas y observación microscópica de amastigotes). Durante los 3 años se examinaron un total de 409 pacientes. En 2014 (89 muestras) se registraron 22 casos positivos (24,7\%); en 2015 (164 muestras) se detectaron 39 casos positivos (23,7\%) y en 2016 (156 muestras) se revelaron 56 pacientes positivos $(35,8 \%)$. En todos los casos los caninos fueron positivos a ambos métodos diagnósticos. En el total de años estudiados, la prevalencia en caninos fue de $28,06 \%$. Se enfatiza que ante los pacientes sospechosos de padecer leishmaniosis visceral, se efectúen conjuntamente los métodos diagnósticos serológico (indirecto) y parasitológico (directo).
\end{abstract}

Palabras clave: canino, leishmaniosis, casuística, métodos diagnósticos.

\begin{abstract}
Maidana, H. R.; P.Gianeselli, M.; Báez, A.D.; Cabrera, W.R.; Llano, E.G.: Casuistry of canine visceral leishmaniosis registered in Corrientes (Argentina) during the period 2014-2016. Rev. Vet. 30: 1, 68-69, 2019. Since the years 2014 to 2016, cases of visceral leishmaniosis were investigated in canines examined at the Faculty of Veterinary Sciences of Corrientes, Argentina. The study was carried out through the indirect method (detection of antibodies against the rk39 antigen in venous blood serum) and the direct test (extraction of bone marrow by ribs puncture and microscopic observation of amastigotes). During these three years, 409 patients were examined. In 2014 there were $22 / 89$ positive cases $(24.7 \%)$, in 2015 there were $39 / 164$ positive cases $(23.7 \%$ ) and in 2016 there were $56 / 156$ positive patients (35.8\%). In all cases, the canines were positive for both methods. The average prevalence of leishmaniosis in canines studied during this period was $28.6 \%$. It is emphasized that in presence of patients suspected of suffering visceral canine leishmaniosis, serological (indirect) and parasitological (direct) diagnostic methods should be performed together.
\end{abstract}

Key words: canine, leishmaniosis, casuistry, diagnostic methods.

\section{INTRODUCCIÓN}

La región nordeste de Argentina reúne las condiciones geográficas y climáticas adecuadas para el asentamiento y diseminación de la leishmaniosis visceral canina (LVC), problema creciente en la salud pública debido a que afecta tanto a perros domésticos como a personas. En los caninos su incidencia es elevada, siendo considerados como el reservorio principal de la enfermedad en su ciclo urbano. La sintomatología clínica es variada, generando dificultades diagnósticas.

Recibido: 4 octubre 2018 / Aceptado: 17 diciembre 2018
La leishmaniosis es una enfermedad zoonótica de alta prevalencia en diferentes regiones tropicales y subtropicales del mundo ${ }^{1}$. En el norte de Argentina se han detectado casos y epidemias de "leishmaniasis cutánea americana" desde $1916^{2,3}$. En áreas endémicas del Nuevo Mundo, la magnitud de la afección ha cambiado poco en los últimos 50 años ${ }^{4,5}$.

Los resultados de un relevamiento realizado en Corrientes (Argentina), demuestran la expansión del vector de la enfermedad hacia el sur del país. Recientemente tres nuevas provincias (Chaco, Entre Ríos y Santa $\mathrm{Fe}$ ) se incorporaron como áreas vulnerables de transmisión de LVC. 
En relación con el agente etiológico de las diversas formas clínicas que ocurren en América del Sur, existe un creciente interés entre los investigadores para lograr un diagnóstico eficaz y sensible de estos parásitos.

Actualmente los métodos de rutina más utilizados como diagnóstico son: el método parasitológico directo (observación del parásito en frotis de médula ósea o linfonódulos) y el método serológico indirecto (prueba inmunocromatográfica, Kalazar detect canine rK39), prueba cualitativa que permite en pocos minutos la detección de anticuerpos anti-LVC en sueros caninos, con una sensibilidad de $80-97 \%{ }^{6}$.

\section{MATERIAL Y MÉTODOS}

El trabajo se efectuó investigando a los pacientes caninos ingresados al Hospital de Clínica de Pequeños Animales de la Facultad de Ciencias Veterinarias de Corrientes (Argentina). Ante la presencia de síntomas sospechosos de LVC fueron derivados al Servicio de Diagnóstico de Leishmaniosis Visceral Canina.

La investigación se desarrolló durante los meses de febrero a octubre de los años 2014, 2015 y 2016. Consistió en la extracción de sangre de la vena cefálica del antebrazo, separación del suero mediante centrifugación y confrontación del mismo con los anticuerpos de la tira reactiva inmunocromatográfica rápida (Kalazar Detec Canine, rK39) y por otro lado, la toma de muestra de médula ósea mediante punción-aspiración con aguja fina, de la parte distal de las tres últimas costillas de los caninos en cuestión, efectuándose frotis que previo fijado con alcohol etílico $96^{\circ}$ fueron coloreados con Giensa y posteriormente examinados en microscopio óptico.

\section{RESULTADOS}

De un total de 409 pacientes estudiados por ambos métodos diagnósticos durante los 3 años, se observó que en 2014 (89 pacientes) hubo 22 positivos (24,7\%); en el año 2015 (164 pacientes) se registraron 39 positivos $(23,7 \%)$ y durante 2016 (156 pacientes) se diagnos-

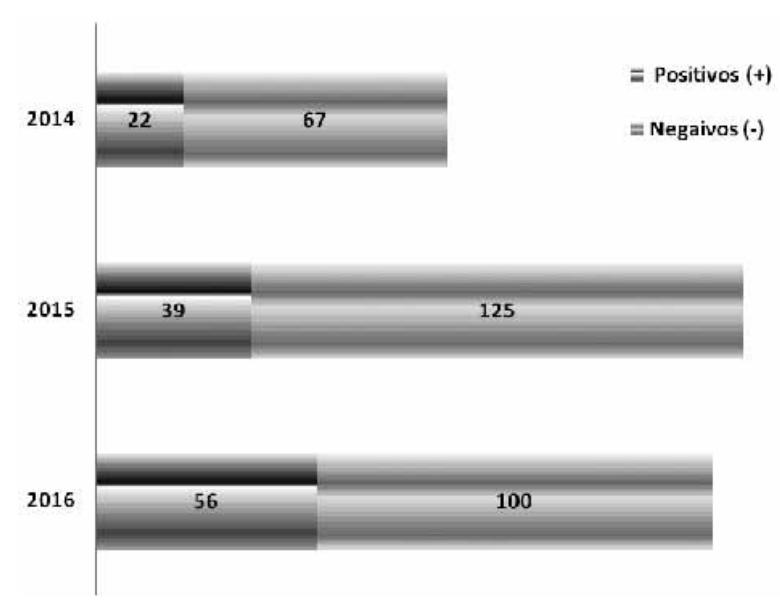

Figura 1. Porcentajes de animales positivos y negativos (ambos métodos), según el año. ticaron 56 pacientes positivos $(35,8 \%)$. En la Figura 1 se resaltan las cifras de caninos positivos y negativos registrados en cada uno de los tres años mencionados.

El Servicio de Diagnóstico de Leishmaniosis Visceral Canina considera caso confirmado a todo paciente sospechoso que haya revelado un diagnóstico confirmatorio de la afección por serología y parasitología, esta última considerada de mayor sensibilidad.

En conclusión, surge que en el periodo de tres años, luego de examinar un total de 409 pacientes ingresados al Hospital de Clínica, 117 caninos acusaron resultado positivo, lo cual constituye una prevalencia del $28,6 \%$, tornando ostensible la necesidad de profundizar los diagnósticos parasitológicos y serológicos, así como encarar acciones que preserven la salud de caninos y seres humanos.

Agradecimientos. A Ricardo Ledesma y Ariel Mouchard, por su aporte en el trabajo del Servicio de Diagnóstico de Leishmaniosis Visceral.

\section{REFERENCIAS}

1. Baneth G, Koutinas AF, Solano L. 2008. Canine leishmaniosis, news concepts and insights on an expanding zoonosis. Trends in Parasit. 24: 324-330.

2. Ciarantella P, Oliva T, Deluna R. 1997. A retrospective clinical study of canine leishmaniasis in 150 dogs naturally infected by Leishmanía infantum. Vet. Record 141: 539-543.

3. Ferrer L, Aisa MJ, Roura X, Porras M. 1995. Serological diagnosis and treatment of canine leishmaniasis. Vet. Record 136: 514-516.

4. Llanos CA. 2004. Report of the Scientific Working Group on Leishmaniasis, TDR/SWG/04. http://www.who.int/tdr/ publications/documents/swg_leish.pdf.

5. Newton A, Steurer F, Schantz P, Giger U. 2001. Transmission of visceral leishmaniasis through blood transfusions from infected English foxhounds to anemic dogs. $J$ Am Vet Med Assoc 219: 1076-1083.

6. Romero MH, Sánchez JA. 2007. El diagnóstico de la leishmaniasis visceral canina (Leishmania infantum). Vet Zootec 1: 51-59. 